\title{
South Asians and coronary heart disease: always bad news?
}

Latest data from the 2001 UK Census noted that, although coronary mortality fell among all migrants, rate ratios for coronary mortality remain higher for men and women of south Asian origin. ${ }^{1}$ Ethnic inequalities in coronary heart disease (CHD) therefore continue to exist and justify the significant and commendable efforts of the UK's National Health Service (NHS) to address these inequalities.

Ethnic disparities in CHD mortality continue to be reported from around the globe. Sheth et al reported on cardiovascular mortality among Canadians of European, south Asian, or Chinese origin from 1979 to $1993 .{ }^{2}$ In their analysis of 1.2 million deaths, rates of death from ischaemic heart disease were highest among Canadians of south Asian origin, whereas those of Chinese origin had a substantially lower rate.

Before we discuss the causes of ethnic disparities in CHD, one must be cognisant of the fact that south Asians are a heterogeneous group and therefore important differences do exist between specific ethnic groups, not only in disease outcomes but also risk factor profiles too. These differences are too extensive to be addressed in this short summary but more detailed accounts are accessible elsewhere. ${ }^{3}$

\section{CHD RISK FACTORS AND ETHNICITY}

It is well known that south Asians have substantially higher rates of diabetes, and this is often the risk factor most blamed for their higher CHD mortality. ${ }^{4}$ In a prospective cohort study conducted of 828 south Asian and 27962 non south Asian patients in the UK with insulintreated diabetes, the standardised mortality ratio for south Asians diagnosed with diabetes before 30 years of age was $3.9(95 \% \mathrm{Cl}=2.0$ to 6.9$)$ in men and 10.1 $(95 \% \mathrm{Cl}=5.6$ to 16.6$)$ in women; in corresponding non south Asian men and women, the figures were $2.7(95 \% \mathrm{Cl}=$ 2.6 to 2.9$)$ and $4.0(95 \% \mathrm{Cl}=3.6$ to 4.3$)$ respectively. ${ }^{5}$

That diabetes mellitus may have a worse prognosis in south Asians for future adverse coronary outcomes and diabetes-related complications has been proposed by others, ${ }^{6}$ with the finding that south Asian patients have poorer knowledge and understanding of diabetes $^{7}$ may play a significant role.

An innate predisposition from a young age,$^{8}$ superimposed with environmental and behavioural factors, precipitates insulin resistance, and this largely explains the high prevalence of type 2 diabetes in south Asians. In parallel, the prevalence of lower physical activity rates is higher in south Asian populations ${ }^{9}$ and poses a challenge to improving overall health and wellbeing, both for primary and secondary prevention.

The prevalence of other conventional or so called 'classical' risk factors also differs by ethnic group, but prevalence is not necessarily higher in south Asian populations, with lower levels of total cholesterol and smoking prevalence than the white European majority population ${ }^{10}$ and similar levels of hypertension. ${ }^{11}$ Intuitively, this raises the potential for potency of risk factors or their interaction to differ in different ethnic groups.

While family history of premature cardiovascular disease is a complex risk factor to quantify and use in risk prediction, there is no doubt that south Asian patients, from Bangladeshis in London to Indians in the US, present with coronary disease at younger ages than white European patients, ${ }^{12}$ age being the most important non-modifiable risk factor in the aetiology and prognosis of $\mathrm{CHD}$ from large population studies, such as the Framingham Heart Study and the World Health Organization MONICA (Multinational MONItoring of trends and determinants in CArdiovascular disease) Project.

\section{Socio-environmental factors}

The comparative prognosis of $\mathrm{CHD}$ in south Asian and white European patients may be affected by a range of factors that are not only biological but also social. Previous research has shown a clear social gradient in CHD outcomes, a higher socioeconomic status being associated with a lower coronary mortality, ${ }^{13}$ and that living in an area of social deprivation influences aetiology and prognosis of coronary disease. ${ }^{14}$ Deprivation per se is not a risk factor for CHD in south Asians but, as in the white European population, is a social determinant of risk factors. South Asian populations are more likely to live in areas with relative social and economic deprivation. ${ }^{15}$

\section{Access to care}

Studies reporting that south Asian patients have received inferior or inequitable clinical management suggest that this may be attributed to poor access secondary to geographical location, associated with the deprived areas that they live in. ${ }^{16}$

However, the relationship between social environment and minority ethnic group health is not necessarily a negative one in terms of access. Distance from hospital is a prognostic factor for all patients - in a study examining ambulance journeys to hospital of patients with potentially life-threatening conditions, increased distance from hospital was associated with increased risk of death (odds ratio 1.02 per kilometre; $95 \% \mathrm{Cl}=1.01$ to 1.03 ; $P<0.001)$. This association was not changed by adjustment for confounding by age, sex, clinical category, or illness severity. ${ }^{17}$ This is of relevance to prognostic analyses in CHD as minority ethnic groups in the UK tend to live closer to acute hospitals. ${ }^{18}$

It has long been recognised that access to coronary revascularisation services may, paradoxically, be increased 
in deprived areas in the UK, probably as a result of their proximity to specialist cardiac centres, such as teaching hospitals. ${ }^{19}$ Therefore, the issue of inequitable access to services is not simply one of inequitable provision, but an interplay of awareness, physical access, acceptability of services and, ultimately, acquisition of services.

\section{CLINICAL MANAGEMENT}

\section{Primary prevention}

The recently launched NHS Health Check programme defines ethnicity as a recordable item in the baseline minimum dataset, which in due course will provide valuable information on disparities. NHS Health Check is a highly commendable programme giving primary care an opportunity to target those at greatest risk of $\mathrm{CHD}$ and, consequently, shift towards a strategy to predict and prevent, rather than diagnose and treat for CHD. The introduction of pay for performance incentives in UK primary care has been shown to be associated with better and more equitable management of $\mathrm{CHD}$ across ethnic groups. ${ }^{20}$

\section{Clinical care}

Patient outcomes are tempered by variations in receipt of medical treatment, such as statins, ${ }^{21}$ as well as access to hospital processes of care, such as angiography, and subsequent receipt of coronary revascularisation. Underuse of appropriate medical treatment in a particular ethnic group will potentially worsen their prognosis.

In patients with angina, those of south Asian origin have previously been reported to be less likely to undergo specialist investigation than those of white European origin. ${ }^{22}$ This may not be solely explained by access to specialist services, as general practices with a higher proportion of south Asian patients have been reported as having higher rates of coronary angiography. ${ }^{23}$ Furthermore, south Asians were more likely to seek immediate care for (hypothetical) angina symptoms than white European people ${ }^{24}$ in a survey of attitudes to health seeking behaviour, and have been reported to have had more consultations with a GP in the year before coronary angiography than white European people..$^{22}$

However, in more contemporary work in populations already selected for coronary angiography, as reported in the appropriateness of coronary revascularisation (ACRE) study in east London, south Asians were not inequitably managed in terms of prescription medication, although they were less likely to undergo coronary revascularisation. ${ }^{22}$ However, those who were revascularised were likely to have less improvement of angina symptoms than white Europeans, although mortality rates did not differ by ethnicity. ${ }^{25}$

More recent studies using data from the 2001 Census and the Quality and Outcomes Framework suggest that medical therapy, such as statin therapy which plays an important role in improving prognosis $^{26}$ is, on the contrary, relatively more highly prescribed in south Asians and more deprived communities. ${ }^{27}$

\section{IMPLICATIONS FOR PRACTICE}

Although ethnic inequalities in $\mathrm{CHD}$ have existed for many decades and continue to exist, healthcare systems are now beginning to respond to these inequalities. Equitable access to care will drive more equitable prognosis when comparing ethnic groups, and recent data already show that this can contribute to the amelioration of previously observed ethnic inequities in outcomes.

From an incident risk perspective, however, a different potency is observed in south Asians compared to white Europeans. The increased predisposition to diabetes and continuing increased incidence of coronary disease in south Asians $^{28}$ continues to pose a significant challenge warranting not only prevention strategies to be robust, but also the need to be implemented truly at a population level, beginning with behavioural change early in life to modify risk. This is where primary care must focus to add a preventive armoury to already significant achievements in management of alreadymanifest disease. ${ }^{29}$

The continued presence of premature $\mathrm{CHD}$ at disproportionate rates in south Asians suggests there is still more to do. A strategy of addressing social determinants of CHD and implementing primary prevention equitably to complement high quality secondary prevention is needed. Primary care is well placed to rise to these challenges.

\section{Justin S Zaman,}

Clinical Lecturer in Cardiology and Epidemiology, University College London and Hospitals and Chair, Cardiovascular Working Group, and Deputy Chair of Trustees, South Asian Health Foundation.

\section{Kiran C R Patel,}

Consultant Cardiologist and Honorary Senior Lecturer, Sandwell and West Birmingham NHS Trust and University of Birmingham) and Clinical Director, NHS West Midlands Strategic Health Authority.

\section{Provenance}

Freely submitted; peer reviewed.

\section{REFERENCES}

1. Harding S, Rosato M, Teyhan A. Trends for coronary heart disease and stroke mortality among migrants in England and Wales, 1979-2003: slow declines notable for some groups. Heart 2008; 94(4): 463-470.

2. Sheth T, Nair C, Nargundkar M, et al. Cardiovascular and cancer mortality among Canadians of European, south Asian and Chinese origin from 1979 to 1993: an analysis of 1.2 million deaths. CMAJ 1999; 161(2): 132-138.

3. Patel KCR, Bhopal R. The epidemic of coronary heart disease in South Asian populations: causes and consequences. Birmingham: The South Asian Health Foundation, 2004

4. Patel KC, Bhopal R. Diabetes epidemic in the South Asian Diaspora: action before desperation. J R Soc Med 2007; 100(3): 115-116.

5. Swerdlow AJ, Laing SP, Dos Santos Silva I, et al. Mortality of South Asian patients with insulin-treated diabetes mellitus in the United Kingdom: a cohort study. Diabet Med 2004; 21(8): 845-851.

6. McElduff P, Edwards R, Burns JA, et al. Comparison of processes and intermediate outcomes between South Asian and European patients with diabetes in Blackburn, north-west England. Diabet Med 2005; 22(9): 1226-1233.

7. Rankin J, Bhopal R. Understanding of heart disease an diabetes in a South Asian community: cross-sectional study testing the 'snowball' sample method. Public Health 2001; 115(4): 253-260.

8. Whincup PH, Gilg J, Papacosta O, et al. Early evidence of ethnic differences in cardiovascular risk: cross sectional comparison of British South Asian and white children BMJ 2002; 324(7338): 635.

9. Fischbacher CM, Hunt S, Alexander L. How physically active are South Asians in the United Kingdom? A literature review. J Public Health 2004; 26(3): 250-258.

10. Lyratzopoulos G, McElduff P, Heller RF, et al. Mid-term Body Mass Index increase among obese and non-obese individuals in middle life and deprivation status: a cohort Study. BMC Public Health 2005; 5:32.

11. Agyemang C, Bhopal RS. Is the blood pressure of South Asian adults in the UK higher or lower than that in European white adults? A review of cross-sectional data. J Hum Hypertens 2002; 16(11): 739-751.

12. Wilkinson P, Sayer J, Laji K, et al. Comparison of case fatality in south Asian and white patients after acute myocardial infarction: observational study. BMJ 1996; 
312(7042): 1330-1333.

13. Hemingway H, Shipley M, Macfarlane P, Marmot M. Impact of socioeconomic status on coronary mortality in people with symptoms, electrocardiographic abnormalities, both or neither: the original Whitehall study 25 year follow up. J Epidemiol Community Health 2000; 54(7): 510-516.

14. Diez Roux AV, Merkin SS, Arnett D, et al. Neighborhood of residence and incidence of coronary heart disease. N Engl J Med 2001; 345(2): 99-106.

15. Acheson D. Independent inquiry into inequalities in health. London: The Stationery Office, 1998.

16. Sekhri N, Timmis A, Chen R, et al. Inequity of access to investigation and effect on clinical outcomes: prognostic study of coronary angiography for suspected stable angina pectoris. BMJ 2008; 336(7652): 1058-1061.

17. Nicholl J, West J, Goodacre S, Turner J. The relationship between distance to hospital and patient mortality in emergencies: an observational study. Emerg Med J 2007; 24(9): 665-668.

18. Stone M, Galbraith J. How not to fund hospital and community health services in England. J R Statist Soc 2006; 169(1): 143-164. (Article first published online: 8 Nov 2005, DOI: 10.1111/j.1467-985X.2005.00392.x)

19. Black N, Langham S, Petticrew M. Coronary revascularisation: why do rates vary geographically in the UK? J Epidemiol Community Health 1995; 49(4): $408-412$.

20. Millett C, Gray J, Wall M, Majeed A. Ethnic disparities in coronary heart disease management and pay for performance in the UK. J Gen Intern Med 2009; 24(1): $8-13$.

21. Patel MG, Wright DJ, Gill PS, et al. Prescribing of lipid lowering drugs to South Asian patients: ecological study. BMJ 2002; 325(7354): 25-26.

22. Feder G, Crook AM, Magee P, et al. Ethnic differences in invasive management of coronary disease: prospective cohort study of patients undergoing angiography. BMJ 2002; 324(7336): 511-516.

23. Jones M, Ramsay J, Feder G, et al. Influence of practices' ethnicity and deprivation on access to angiography: an ecological study. Br J Gen Pract 2004; 54(503): 423-428.

24. Chaturvedi N, Rai H, Ben-Shlomo Y. Lay diagnosis an health-care-seeking behaviour for chest pain in south Asians and Europeans. Lancet 1997; 350(9091): 1578-1583.

25. Zaman MJ, Crook AM, Junghans C, et al. Ethnic differences in long-term improvement of angina following revascularization or medical management: a comparison between south Asians and white Europeans. J Public Health 2009; 31(1): 168-174.

26. Ferrières J, Cambou JP, Guéret P, et al. Effect of early initiation of statins on survival in patients with acute myocardial infarction (the USIC 2000 Registry). Am J Cardiol 2005; 95(4): 486-489.

27. Ashworth M, Lloyd D, Smith RS, et al. Social deprivation and statin prescribing: a cross-sectional analysis using data from the new UK general practitioner 'Quality and Outcomes Framework' Public Health (Oxf) 2007; 29(1): 40-47.

28. Zaman MJ, Shipley MJ, Stafford M, et al. Incidence and prognosis of angina pectoris in South Asians and Whites: 18 years of follow-up over seven phases in the Whitehall-II prospective cohort study. J Public Health (Oxf) 2010; Nov 2 (Epub ahead of print).

29. Patel KC, Spilsbury P, Shukla R. Clinical contributions to addressing the social determinants of health. Clin Med 2010; 10(2): 130-133.

DOI: 10.3399/bjgp11X548901

\section{ADDRESS FOR CORRESPONDENCE}

M Justin S Zaman

Clinical Epidemiology group, UCL, 1-19 Torrington Place, London. WC1E 6BT.

E-mail: drjustinzaman@sahf.org.uk 